\title{
BMJ Open Profiles of children's social-emotional health at school entry and associated income, gender and language inequalities: a cross-sectional population-based study in British Columbia, Canada
}

Kimberly C Thomson, ${ }^{1,2}$ Martin Guhn, ${ }^{1,2}$ Chris G Richardson, ${ }^{2,3}$ Tavinder K Ark, ${ }^{1,2}$ Jean Shoveller ${ }^{2}$

To cite: Thomson KC, Guhn M, Richardson CG, et al. Profiles of children's social-emotional health at school entry and associated income, gender and language inequalities: a cross-sectional populationbased study in British Columbia, Canada. BMJ Open 2017;7:e015353. doi:10.1136/ bmjopen-2016-015353

- Prepublication history for this paper is available online. To view these files please visit the journal online (http://dx.doi. org/10.1136/bmjopen-2016015353).

Received 29 November 2016 Revised 1 June 2017 Accepted 6 June 2017

\section{CrossMark}

${ }^{1}$ Human Early Learning Partnership, School of Population and Public Health, University of British Columbia, Vancouver, BC, Canada

${ }^{2}$ School of Population and Public Health, University of British Columbia, Vancouver, BC, Canada

${ }^{3}$ British Columbia Centre for Health Evaluation and Outcome Sciences, Vancouver, BC, Canada

Correspondence to Kimberly C Thomson; kimberly.thomson@ubc.ca

\section{ABSTRACT}

Objectives Early identification of distinct patterns of child social-emotional strengths and vulnerabilities has the potential to improve our understanding of child mental health and well-being; however, few studies have explored natural groupings of indicators of child vulnerability and strengths at a population level. The purpose of this study was to examine heterogeneity in the patterns of young children's social and emotional health and investigate the extent to which sociodemographic characteristics were associated.

Design Cross-sectional study based on a population-level cohort.

Setting All kindergarten children attending public schools between 2004 and 2007 in British Columbia (BC), Canada. Participants 35818 kindergarten children (age of 5 years) with available linked data from the Early Development Instrument (EDI), BC Ministry of Health and BC Ministry of Education.

Outcome measure We used latent profile analysis (LPA) to identify distinct profiles of social-emotional health according to children's mean scores across eight socialemotional subscales on the EDI, a teacher-rated measure of children's early development. Subscales measured children's overall social competence, responsibility and respect, approaches to learning, readiness to explore, prosocial behaviour, anxiety, aggression and hyperactivity. Results Six social-emotional profiles were identified: (1) overall high social-emotional functioning, (2) inhibitedadaptive (3) uninhibited-adaptive, (4) inhibited-disengaged, (5) uninhibited-aggressive/hyperactive and (6) overall low social-emotional functioning. Boys, children with English as a second language (ESL) status and children with lower household income had higher odds of membership to the lower social-emotional functioning groups; however, this association was less negative among boys with ESL status.

Conclusions Over $40 \%$ of children exhibited some vulnerability in early social-emotional health, and profiles were associated with sociodemographic factors. Approximately $9 \%$ of children exhibited multiple
Strengths and limitations of this study

- Strengths of this study included the use of a large population-level data set to explore patterns of children's social-emotional health from a unique person-centred perspective.

- Measures of children's relative strengths were included in addition to measures of vulnerability.

- The cross-sectional design and dichotomisation of sociodemographic factors provided a descriptive first look at the data that should be followed up with more nuanced analyses.

- Our analyses distinguished profiles of relative socialemotional health, but do not speak to absolute levels of clinical risk.

co-occurring vulnerabilities. This study adds to our understanding of population-level distributions of children's early social-emotional health and identifies profiles of strengths and vulnerabilities that can inform future intervention efforts.

\section{INTRODUCTION}

Social-emotional vulnerabilities in early childhood, including problems with anxiety, depressive symptoms, hyperactivity and aggression, can severely impact children's social and psychological well-being. It has been estimated that $14 \%-26 \%$ of children exhibit diagnosable psychiatric symptoms before school entry ${ }^{1}$ and while there is some variation in the continuity of symptoms as children age (some studies suggest behavioural problems decrease whereas emotional problems increase), ${ }^{2}$ early impairments are found to remain relatively stable throughout the life-course and can become 
exacerbated as children accumulate experiences with social rejection and academic failure. ${ }^{13-6}$ For example, in a 10-year longitudinal study, ${ }^{3}$ social competence at the age of 4 years uniquely predicted adolescent internalising (depressive symptoms and anxiety) and externalising problems (aggression and hyperactivity) beyond children's initial emotional adjustment levels, emphasising the interconnectedness of social and emotional functioning and importance of early social acceptance and self-regulation. ${ }^{78}$ Past studies have also found that early-onset and co-occurring social and emotional problems are more likely to follow a stable or increasing pattern over time, predicting increased odds of psychiatric diagnoses in adulthood as well as decreased occupational opportunities and income, particularly for women. ${ }^{5910}$

Despite the evidence demonstrating the life-course implications of early social and emotional health, there has been relatively limited research dedicated to early detection of subclinical presentations with the goal of early intervention. As McGorry et al argue ${ }^{11}$ within the field of psychiatry, there has been an overemphasis on treatment once problems reach a clinical stage, whereas identifying early-potentially modifiable-biomarkers of vulnerability (eg, neurological indicators of stress) is likely to be more successful. We extend this argument to suggest that identifying patterns of early psychosocial functioning from a 'social-emotional health' perspective may inform efforts to reduce risk for later mental health challenges, particularly during school entry when children are transitioning to a new social environment and undergo rapid changes in social and cognitive development. $^{1213}$

To date, much of the evidence regarding children's social-emotional health has come from non-population-based studies that compare group differences across levels of a particular symptom, such as depressed mood. ${ }^{514} 15$ These variable-centred methods can be effective for identifying children with elevated depressive symptoms. However, such approaches also imply a homogeneous distribution of such factors within risk groups. Conversely, many studies have shown that children are more likely to experience clusters of symptoms at various moments in the life-course that may influence subsequent developmental outcomes in less uniform ways, in accordance with a child's unique combination of comorbidities and environmental supports and challenges. ${ }^{9}{ }^{10}{ }^{16-19}$ To address this limitation, person-centred methods and statistical approaches (including latent profile analysis (LPA)) have been used to examine heterogeneity within population subgroups (eg, based on shared symptoms, severity of symptom and age of onset).${ }^{18} 2021$ Not only can these methods better account for diverse constellations of symptoms experienced by a range of children, they can further identify commonly co-occurring strengths that may be leveraged to inform intervention efforts. For example, meta-analyses have found the most effective prevention programmes for addressing internalising problems target the reduction of negative cognitions, as well as the promotion of positive thoughts, actions and social skills (eg, Blues Program, Coping with Stress). ${ }^{22-24}$ Similarly, universal schoolbased programmes that focus on malleable skills, such as self-awareness, self-management, social awareness, relationship skills and responsible decision-making, have been shown to be effective for reducing emotional distress as well as reducing externalising problems such as conduct problems and aggression..$^{25} 26$

Person-centred approaches may also help to identify sociodemographic characteristics that are associated with particular population subgroups for the purpose of indicating early social disparities that may contribute to the onset of more severe outcomes among subgroups of equally vulnerable children. ${ }^{19}{ }^{27-29}$ For example, several studies have reported boys exhibit higher externalising behaviour than girls, although this evidence is mixed. ${ }^{29-31}$ Socioeconomic hardship generally predicts lower socialemotional functioning in children, for example, through strained primary caregiver relationships, but again this finding is inconsistent. ${ }^{9} 27283132$ Finally, children who are newcomers to Canada may face language barriers (ie, limited English/French proficiency) associated with lower perceived social skills, ${ }^{33}$ and may also experience distress from navigating different cultures at home and at school, potentially increasing children's anxiety and depression. ${ }^{34}$ Few studies have examined this combination of multiple sociodemographic factors. However, the existing evidence suggests the presence of theoretically and practically important interaction effects-for example, some stressors within children's home environments seem to increase the risk of internalising for girls, but not for boys. ${ }^{36}$

\section{Objectives and hypotheses}

Although there is burgeoning evidence that distinct social-emotional patterns emerge in early childhood, there are still significant knowledge gaps including how positive indicators combine with problem behaviours to form different constellations or 'profiles', how the prevalence of such profiles may be distributed in the population and how profiles may be jointly associated with multiple sociodemographic characteristics. The current study sought to investigate: (1) whether distinct profiles of early social-emotional health could be identified among children at school entry and (2) whether household income level (measured as receiving a government subsidy), child gender and child English as a second language (ESL) status would be associated with profile membership singularly and in combination. Based on the existing literature, we hypothesised (1) distinct profiles of social-emotional health would be observable at this age,and (2) children from lower income families, boys and children with ESL status would be over-represented in the lowest social-emotional health profile groups. 


\section{METHODS}

\section{Data source}

Data were obtained from a population sample of children attending kindergarten across all public schools in British Columbia (BC), Canada, between 2004 and 2007..$^{37}$ Within BC, parents are advised to register their child for school or home schooling in the year their child turns 5 years, although legally parents may choose to defer their child's schooling for one more year. ${ }^{38}$ During the study period, $87.5 \%$ of children attending Kindergarten were enrolled in public schools compared with $12.5 \%$ enrolled in independent schools or home schooling. ${ }^{39}$ Parents who enrol their children in independent schools are often more affluent; ${ }^{40}$ therefore, our public school sample may have under-represented families at higher income levels. Regarding language status, enrolment statistics for that period indicated that $94.5 \%$ of Kindergarten students identified as English language learners (16.7\% of the BC population) attended public school ${ }^{39}$ (English is the primary language of instruction in BC). Children's social-emotional health was measured using the Early Development Instrument (EDI), a validated teacher-report measure of children's school readiness routinely administered during the Kindergarten year of schooling. ${ }^{41-43}$ EDI records were linked to children's gender, ESL status and health insurance subsidy status (a proxy for household poverty level) with permission from the British Columbia Ministries of Health and Education. Ethics approval was obtained from the University of British Columbia Research Ethics Board.

\section{Measures}

Eight indicators of children's social-emotional health were measured using subscales from the $\mathrm{EDI}^{41}$ : overall social competence (five items), responsibility and respect (eight items), approaches to learning (nine items), readiness to explore (four items), prosocial and helping behaviour (eight items), anxious and fearful behaviour (eight items), aggressive behaviour (seven items), and hyperactive and inattentive behaviour (seven items). Example items, means and standard deviations (SD) are provided in table 1 . On the EDI, teachers are asked to select one of four response options that best describes each of their students' behaviour currently or within the last 6 months. 'Never or not true' is assigned a score of 0 , 'Sometimes or somewhat true' is assigned a score of 5 and 'Often or very true' is assigned a score of 10. 'Don't know' is coded as missing. Negatively worded items, such as 'is upset when left by parent/guardian', are reverse-coded so that higher scores indicate better social-emotional health.

Household subsidy status was derived from Medical Services Plan (MSP) records and used as an indicator of relative poverty. Subsidy status was split into two categories: ' $100 \%$ subsidy' and 'no subsidy.' During the data collection period, $100 \%$ subsidy was available to a family of any size that earned an annual net income $<\$ 22000$ Canadian dollars. In contrast, no subsidy was available for families who earned an annual net income $>\$ 30000$ Canadian dollars. Ninety percent of households within the sample were included in one of these two categories. The remaining $10 \%$ of households had incremental coverage (20\%-80\% subsidy) or were eligible for temporary subsidy or disability assistance. These categories were excluded due to their low frequency. In instances where the same child had multiple subsidy codes associated with their health record, we used the earliest code based on life-course theory that suggests earlier experiences have greater impact over child development outcomes. ${ }^{44}$ Teachers reported each child's sex as 'male' or 'female'. These categorisations were then cross-validated with children's sex from BC Ministry of Education records. ESL status was also reported by teachers and cross-validated with Ministry records. ESL status is a designation which schools use to apply for additional resources to support children's learning needs. We selected these three sociodemographic factors based on their theoretical and applied relevance in developmental and epidemiological research and representativeness of the diversity of children in the population under study.

\section{Analyses}

Identifying latent profiles

LPA using MPlus V. $7^{45}$ was used to identify unique patterns (ie, profiles) of social-emotional health in the

Table 1 EDI social-emotional health subscales: means and distributions

\begin{tabular}{lll}
\hline EDI subscale & Example items & Unstandardised mean (SD) \\
\hline Overall social competence & Gets along with peers & $7.45(2.48)$ \\
Responsibility and respect & Follows rules, respects others & $8.43(2.13)$ \\
Approaches to learning & Completes work on time & $7.91(2.28)$ \\
Readiness to explore & Eager to play a new game & $8.86(1.99)$ \\
Prosocial and helping behaviour & Offers to help others & $5.53(3.02)$ \\
Anxious and fearful & Nervous, cries a lot & $8.78(1.63)$ \\
Aggressive behaviour & Temper tantrums, fights & $9.22(1.52)$ \\
\hline Hyperactive and inattentive & Distractible, impulsive & $8.09(2.52)$ \\
\hline
\end{tabular}

*Scales range from 0 to 10 with higher scores indicating better social-emotional health.

EDI, Early Development Instrument. 
population sample. LPA is a type of finite mixture modelling that assesses the ability of grouped underlying latent classes to explain the variance among a set of observed dependent variables (ie, children's scores on each of the eight social-emotional subscales from the EDI). ${ }^{46} 47$ For ease of interpretation, we first standardised all eight social-emotional subscale scores within the population sample so that every indicator had a mean of 0 and SD of 1 . We then entered the standardised scores into MPlus to conduct the LPA, using all available data points (ie, all cases were included unless they had missing data on all eight social-emotional subscales). Because we tested several models with a large number of class solutions (>3 classes), we set random starting values to $500 \quad(50$ iterations) in order to avoid increasing statistical inaccuracy or biasing parameter estimates. ${ }^{48}$ Starting with a one-class model, we ran multiple class solutions to determine the best fitting solution. Relative model fit was assessed according to four standard criteria provided by Geiser $^{48}$ and Nylund et $a t^{49}$ : (1) entropy score closest to 1 , indicating good classification accuracy; (2) high discrimination between classification probabilities (probability of being assigned to any particular class $\geq 0.8$ ); (3) lowest adjusted Bayesian Information Criterion (aBIC), indicating relatively better fit among nested models and (4) statistically significant Bootstrap Likelihood Ratio Test (BLRT), testing whether a model with $\mathrm{k}$ latent classes fits better than a model with k-1 classes. As recommended, we also considered parsimony, interpretability and theoretical meaningfulness in our selection of the overall best model. ${ }^{449}$

\section{Predicting profile membership}

Once the best fitting model was determined from the LPA, a latent profile membership value was assigned to each child based on their most likely predicted profile membership. We then linked this file (using a unique identifier associated with each child) to a data set containing children's linked EDI-MSP records (ie, household subsidy status, gender and ESL status). Multinomial logistic regression analysis was then used to determine how these sociodemographic characteristics were associated with each profile. All covariates were entered simultaneously to assess the magnitude of association of each sociodemographic factor in the context of all others. Two and three-way interactions were also examined.

\section{RESULTS}

\section{Study population}

Linked MSP records were available for 36321 (95\%) of the children who had EDI data. Within this subset, a further $503(1.4 \%)$ of children were excluded due to missing data on all eight social-emotional subscales comprising the outcome measure. The final analytical sample included 35818 children (mean age $=5.67$, $\mathrm{SD}=0.31$ ). Demographic analysis showed that $18.5 \%$ of children were from households that had received a full subsidy at their earliest healthcare visit, $51.5 \%$ were identified as boys and $17.3 \%$ were identified as ESL status. In comparison, among the $1.4 \%$ of children missing from the analysis, $26.8 \%$ were from households receiving full subsidies, $56.1 \%$ were boys and $27.2 \%$ were ESL status. These children also had a higher mean number of days absent from school compared with children included in the analysis (17.4 days vs 4.7 days). Child age did not differ between groups.

\section{Social-emotional health latent profiles}

Model fit estimations from the LPA suggested six unique profiles of social-emotional health (table 2). Although aBIC scores kept decreasing and BLRT tests were statistically significant with each additional class, the six-class solution was among three solutions with the best entropy and class probability scores, indicating good distinction between classes and high accuracy of being assigned to each class based on the eight social-emotional scores provided. To further distinguish the best fitting model, we

Table 2 Latent profile analysis model fit comparison

\begin{tabular}{|c|c|c|c|c|c|c|c|}
\hline $\begin{array}{l}\text { No of latent } \\
\text { profiles }\end{array}$ & $\begin{array}{l}\text { Log likelihood } \\
\text { value }\end{array}$ & aBIC & Entropy & BLRT & $\begin{array}{l}\text { Lowest class } \\
\text { probability }\end{array}$ & $\begin{array}{l}\text { Smallest } \\
\text { class size }\end{array}$ & $\begin{array}{l}\text { Smallest } \\
\text { class } \\
\text { proportion }\end{array}$ \\
\hline 1 & -400021.73 & 800160.40 & NA & NA & 1 & 35818 & 1.00 \\
\hline 2 & -341163.26 & 682509.22 & 0.95 & 0.00 & 0.97 & 8998 & 0.25 \\
\hline 3 & -323736.06 & 647720.60 & 0.94 & 0.00 & 0.95 & 2981 & 0.08 \\
\hline 4 & -315968.54 & 632251.32 & 0.90 & 0.00 & 0.88 & 1940 & 0.05 \\
\hline 5 & -308638.88 & 617657.79 & 0.95 & 0.00 & 0.93 & 1854 & 0.05 \\
\hline 6 & -302360.31 & 605166.41 & 0.95 & 0.00 & 0.93 & 910 & 0.03 \\
\hline 7 & -298087.32 & 596686.22 & 0.93 & 0.00 & 0.88 & 826 & 0.02 \\
\hline 8 & -295023.77 & 590624.90 & 0.94 & 0.00 & 0.88 & 412 & 0.01 \\
\hline 9 & -291992.24 & 584627.60 & 0.92 & 0.00 & 0.83 & 659 & 0.02 \\
\hline 10 & -289428.48 & 579565.86 & 0.92 & 0.00 & 0.83 & 413 & 0.01 \\
\hline
\end{tabular}

aBIC, adjusted Bayesian Information Criterion; BLRT, Bootstrap Likelihood Ratio Test; NA, not applicable. 


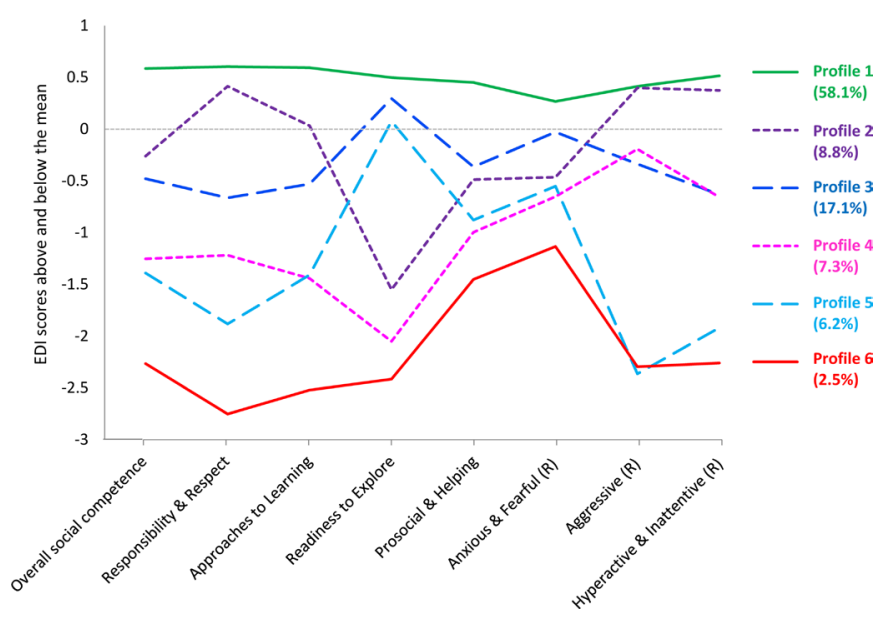

Figure 1 Composition of latent profile groups by EDI social-emotional subscale and prevalence within population sample. Legend: higher scores indicate better socialemotional health. Solid lines represent highest and lowest social-emotional profiles. Long dashes represent higher externalising profiles. Short dashes represent higher internalising profiles. $(\mathbf{R})$ indicates the subscale was reversecoded. EDI, Early Development Instrument.

then calculated the relative change in log likelihood values between nested models and observed larger improvements between the first six solutions, but diminishing returns thereafter. Similar diminishing improvements were observed comparing relative changes in aBIC scores. Acknowledging that determining LPA model fit requires a certain level of subjectivity, Nylund et al recommend that this 'flattening out' effect in model improvement scores can be used as an indicator for model selection. ${ }^{49}$

Within the selected six-class model, the majority of children (58.1\%; Profile 1, overall high social-emotional functioning) were classified together as having high scores (on average, half a SD above the mean) across all eight social-emotional subscales; $41.9 \%$ demonstrated areas of vulnerability on one or more social-emotional subscales. As shown in figure 1, profiles could be observed in parallel patterns. Profile 2 (inhibited-adaptive; $8.8 \%$ ) also demonstrated high social and emotional functioning, but had markedly lower readiness to explore (eg, did not often show interest in a new toy or game and did not often appear curious about the world). Profile 3 (uninhibited-adaptive; $17.1 \%$ ) demonstrated the opposite pattern. These children showed high readiness to explore but slightly lower social skills, such as playing and working cooperatively with peers, following rules and instructions or solving problems independently.

Profiles 4-6, while exhibiting similar patterns of relative strengths and weaknesses as the previous groups, were rated well below the population average on all eight subscales of children's social-emotional health. Profile 4 (inhibited-disengaged; $7.3 \%$ ) showed a parallel pattern to Profile 2 (inhibited-adaptive), with relative strengths in social competence and relative weakness in readiness to explore. Profile 5 (uninhibited-aggressive/hyperactive; $6.2 \%$ ) showed a parallel pattern of strengths and weaknesses to Profile 3 (uninhibited-adaptive); however, Profile 5 showed notably higher vulnerability in aggression and hyperactivity with scores over two SD below the mean. Finally, a small group of children $(2.5 \%$; Profile 6 , overall low social-emotional functioning) were observed as having low social competence and emotional maturity across all scales and scored the lowest of all children on every measure.

\section{Associations with subsidy status, gender and ESL status}

Table 3 provides sociodemographic distributions within each profile group and associated adjusted ORs. Profiles are presented in descending hierarchical order from highest social-emotional health (Profile 1) to lowest (Profile 6). The proportion of children in the subsidy group increased incrementally at each lower level of social-emotional health. Among children in the lowest ranking profile group, $37.1 \%$ received subsidies compared with $16.4 \%$ in Profile 1 . Boys were over-represented in Profiles 5 and 6 that demonstrated high aggression and hyperactivity ( $>76 \%$ boys), and were under-represented in the highest social-emotional health group (43.3\%). Children with ESL status were over-represented in Profiles $2(22.5 \%)$ and $4(24.1 \%)$ demonstrating relative strength in social competence, but lower readiness to explore.

In the multinomial logistic regression analysis, Profile 1 served as the reference to which all other profile groups were compared. In a preliminary model without interactions (results not shown), subsidy status and ESL status were associated with increased odds of membership to each lower social-emotional health group compared with the reference group. Being identified as a boy was also associated with increased odds of membership in the lower social-emotional health profiles, except for Profile 2 (lower readiness to explore). Once interaction terms were included, we observed a statistically significant subadditive interaction between subsidy and language minority status across all five profile comparisons (table 3). ORs smaller than 1.0 indicated that the association between subsidy status and lower social-emotional health was somewhat attenuated for children with ESL status. Three-way interactions were not observed and therefore were excluded from the final model for parsimony.

\section{DISCUSSION}

Using a large population sample of kindergarten children, our application of LPA identified six distinct profiles of social-emotional health, each encompassing a distinct pattern of relative strengths and weaknesses. Consistent with past studies, ${ }^{692732}$ we found that the majority of children fit into a profile demonstrating overall high-social-emotional competence, but that over $40 \%$ of children demonstrated some areas of vulnerability. Profiles 5 and 6 (approximately 9\% of children) exhibited considerably higher aggression and hyperactivity than the others, which is consistent with clinical diagnosis rates for behaviour disorders (eg, oppositional defiant 
Table 3 Latent profile membership distributions and adjusted ORs

$\begin{array}{ll}\text { Profile membership } & \begin{array}{l}\text { Distribution } \\ \text { within } \\ \text { profile }(\%)\end{array} \quad \text { Adjusted OR }(95 \% \mathrm{Cl})\end{array}$

Profile 1 (58.1\%): Overall high social-emotional functioning $(n=20819)$

$\begin{array}{lll}\text { Receiving subsidy } & 16.4 & \text { Ref } \\ \text { Boy } & 43.3 & \text { Ref } \\ \text { ESL } & 15.3 & \text { Ref } \\ \text { Subsidyxboy } & & \text { Ref } \\ \text { SubsidyxESL } & & \text { Ref } \\ \text { BoyxESL } & & \text { Ref }\end{array}$

Profile 2 (8.8\%): inhibited-adaptive $(n=3142)$

\begin{tabular}{|c|c|c|}
\hline Receiving subsidy & 20.8 & $1.33(1.15 \text { to } 1.53)^{\star \star \star}$ \\
\hline Boy & 43.5 & $1.00(0.91$ to 1.11$)$ \\
\hline ESL & 22.5 & $1.80(1.57 \text { to } 2.07)^{\star \star *}$ \\
\hline Subsidy $\times$ boy & & $1.06(0.86$ to 1.29$)$ \\
\hline Subsidy $\times E S L$ & & $0.76(0.61 \text { to } 0.96)^{*}$ \\
\hline Boy $\times E S L$ & & $0.94(0.77$ to 1.14$)$ \\
\hline \multicolumn{3}{|c|}{ Profile 3 (17.1\%): uninhibited-adaptive $(n=6120)$} \\
\hline Receiving subsidy & 21.4 & $1.63(1.44 \text { to } 1.85)^{\star \star *}$ \\
\hline Boy & 64.9 & $2.52(2.34 \text { to } 2.72)^{\star * *}$ \\
\hline ESL & 18.6 & $1.39(1.21 \text { to } 1.60)^{\star \star *}$ \\
\hline Subsidy $\times$ boy & & $0.89(0.76$ to 1.04$)$ \\
\hline Subsidy $\times E S L$ & & $0.64(0.53 \text { to } 0.78)^{\star \star *}$ \\
\hline Boy $\times$ ESL & & 1.03 (0.87 to 1.22$)$ \\
\hline
\end{tabular}

Profile 4 (7.3\%): inhibited-disengaged $(n=2620)$

\begin{tabular}{|c|c|c|}
\hline Receiving subsidy & 27.3 & $2.13(1.80 \text { to } 2.53)^{\star \star \star}$ \\
\hline Boy & 62.4 & $2.44(2.17 \text { to } 2.75)^{\star \star \star}$ \\
\hline ESL & 24.1 & $2.18(1.82 \text { to } 2.61)^{\star \star \star}$ \\
\hline Subsidyxboy & & $0.93(0.76$ to 1.15$)$ \\
\hline Subsidy $\times E S L$ & & $0.67(0.53 \text { to } 0.85)^{\star \star}$ \\
\hline Boy $\times$ ESL & & 0.83 (0.67 to 1.03 ) \\
\hline \multicolumn{3}{|c|}{$\begin{array}{l}\text { Profile } 5(6.2 \%) \text { : uninhibited-aggressive/ } \\
\text { hyperactive }(n=2207)\end{array}$} \\
\hline Receiving subsidy & 28.5 & $2.68(2.14 \text { to } 3.36)^{\star \star \star}$ \\
\hline Boy & 78.9 & $5.19(4.47 \text { to } 6.03)^{\star \star \star}$ \\
\hline ESL & 17.4 & $1.36(1.02 \text { to } 1.82)^{\star}$ \\
\hline Subsidyxboy & & 0.89 (0.69 to 1.15$)$ \\
\hline Subsidy×ESL & & $0.42(0.31 \text { to } 0.55)^{\star \star \star}$ \\
\hline Boy $\times$ ESL & & 1.15 (0.84 to 1.57$)$ \\
\hline
\end{tabular}

Profile 6 (2.5\%): overall low social-emotional functioning $(\mathrm{n}=910)$

\begin{tabular}{lll} 
Receiving subsidy & 37.1 & $4.54(3.32 \text { to } 6.20)^{\star \star \star}$ \\
\hline Boy & 76.9 & $4.50(3.53 \text { to } 5.74)^{\star \star \star}$ \\
ESL & 19.4 & $1.44(0.92$ to 2.24$)$ \\
Subsidyxboy & & $0.79(0.55$ to 1.13$)$
\end{tabular}

Continued
Table 3 Continued

\begin{tabular}{|c|c|c|}
\hline $\begin{array}{l}\text { Profile membership } \\
(\mathrm{N}=35818)\end{array}$ & $\begin{array}{l}\text { Distribution } \\
\text { within } \\
\text { profile (\%) }\end{array}$ & Adjusted OR (95\% Cl) \\
\hline Subsidy $\times E S L$ & & $0.32(0.22 \text { to } 0.48)^{\star \star \star}$ \\
\hline Boy×ESL & & 1.43 (0.89 to 2.30$)$ \\
\hline
\end{tabular}

ORs can be interpreted as the odds of membership to each more vulnerable social-emotional profile group compared with a group with overall high social-emotional functioning. ${ }^{*} p<0.05,{ }^{* *} p<0.01$, ${ }^{* * *} p<0.001$.

ESL, English as a second language.

disorder and attention deficit hyperactivity disorder) among preschool-aged children and underscores how commonly these behaviours co-occur. ${ }^{1}$ However, our results also identified that approximately $6 \%$ of children with these covulnerabilities (Profile 5) also demonstrated considerable strength in their readiness to explore. In contrast, the $3 \%$ of children who did not show this relative strength may represent a group that is more susceptible to chronic mental health problems and that may benefit more from personalised and sustained interventions throughout childhood. ${ }^{50}$

Comparing across Profiles 2 through 5, children who scored higher on the social competence, rule-following and respectfulness scales also generally scored lower on the readiness to explore scale. Conversely, children who scored higher on readiness to explore generally scored lower on these social competence scales. These patterns are consistent with previous person-centred research that has found associations between high extroversion, outgoingness and aggressive/acting out behaviours (ie, 'undercontrollers') and conversely, associations between prosocial behaviour, conscientiousness and high shyness and uneasiness (ie, 'overcontrollers'). ${ }^{30} 5152$ Although both patterns have adaptive elements, neither are considered healthy at high levels. In fact, high levels of these traits (such as those observed in the current study in Profiles 4 and 5) are thought to be differentially predictive of externalising (ie, conduct and hyperactivity problems) and internalising (depressive and anxiety problems) later in life if left unaddressed. ${ }^{305152}$

Regarding these profiles' relation to sociodemographic factors, a second objective of this study was to investigate interactions between household income, gender and ESL status. Consistent with past research, we found that boys were over-represented in the profiles demonstrating high aggression and hyperactivity ${ }^{53}{ }^{54}$ Particularly in school-based contexts, lower behaviour regulation among boys has been associated with disadvantages in academics and student-teacher relationships. ${ }^{55}$ And while symptoms of aggression, impulsiveness and hyperactivity are more often observed among young boys than girls, other research suggests that the same behaviours can be perceived differently by adults, such that teachers and mental health professionals are more likely to refer boys for externalising problems when both boys and girls 
present similar symptoms of hyperactivity. ${ }^{57} 58$ Furthermore, although boys are commonly over-represented in lower social-emotional health groups in childhood, many longitudinal studies found that girls exceed boys in social-emotional vulnerability beginning in early adolescence. ${ }^{559}$

Children identified as ESL were over-represented in the profiles demonstrating lower readiness to explore, which may be indicative of general uncertainty in a new school or even a new country. Halle et al ${ }^{60}$ note that low verbalism of ESL children may also get mistaken by others as 'shyness' which could potentially be the case in our study, although the measure used this study focused more on observable behaviours than dispositions. The observation of a consistent subsidy status $\times$ ESL interaction is another area of interest to investigate with future research. This interaction suggests that poverty was only associated with membership to a more vulnerable social-emotional subgroup for children who spoke English as a first language. There is some support for this in the literature, as strong connections with culture and ethnic identity may increase psychological resilience, ${ }^{61}$ while learning multiple languages may increase attentiveness to social cues. ${ }^{60}$ However, in the current study, we could not control for some potentially relevant sociodemographic or economic confounders (eg, parental education and cultural background). Future studies are required to assess the replicability of the pattern observed in this study, particularly by exploring potential confounding or mediating factors such as number of years in Canada, region of residence, school context, family composition and measures of acculturation including language and media use as well as cultural identity. ${ }^{34} 3562-64$

Finally, similar to Nicholson et $a l^{65}$ who found socioeconomic position to be associated with increased odds of social-emotional difficulties, our analyses identified that children from households that qualified for government subsidies had higher odds of membership to each lower social-emotional health group compared with children who did not qualify for subsidies. Although causality cannot be determined from the study design, the observed social gradient is consistent with patterns observed across numerous other studies investigating early childhood socioeconomic status as a risk factor for future health and mental health outcomes. ${ }^{66-70}$ Unique to the current study, our findings further highlight the complexity of social-emotional vulnerabilities (ie, highly inhibited and uninhibited profiles) and related sociodemographic factors, implicating the role of social forces in the construction of social-emotional problems and (potentially) reflecting our failure to intervene in the case of vulnerabilities we might 'expect' from children based on their income, gender or English language status. At the same time, our results emphasise the universalism of social-emotional vulnerabilities. Notably, the majority of children in the lower social-emotional profiles were not from subsidy-receiving households. Rather, early vulnerabilities appeared to affect children across socioeconomic, gender and ESL status categorisations.

\section{Limitations and future directions}

As a cross-sectional study, the current findings provide a descriptive first look at the population profiles of early social-emotional health. Measuring sociodemographic factors dichotomously results in a loss of information that potentially obscures a more nuanced understanding of the relationships under investigation (eg, non-linear relationships); however, our results provide a useful starting point for the development of future studies. Similarly, a general limitation in this research area is the inconsistency in the measurement of social-emotional health. The EDI showed good discrimination and variability; however, there may be other social or emotional indicators not included in this measure that could be explored in future research. For example, future studies may include indicators that have been targeted in successful school-based interventions, such as self-regulation (self-awareness and self-management) ${ }^{25}$ Although these measures are largely included in the social competence subscales of the EDI (overall social competence, responsibility and respect, and approaches to learning), identifying specific social and emotional skills may facilitate implementation and evaluation of prevention and intervention programmes. Furthermore, our analysis distinguished profiles of relative social-emotional health, but did not speak to absolute levels of clinical risk. Although the EDI has been found have predictive validity in relation to later social and emotional outcomes (eg, the EDI's emotional maturity domain predicts student well-being at 9 years of age) ${ }^{71}$ the EDI is not a diagnostic tool. Rather, it is a measure of population health that was used uniquely in this study to assess the variation and prevalence of symptom patterns within the BC population of Kindergarten children. Teachers' ratings on the EDI also do not capture how children behave outside of school, and may therefore be more accurately interpreted as a measure of children's social-emotional health in a school-based context. ${ }^{72}$ Our analysis of missing data indicated that our sample under-represented children from lower income and ESL households; however, this would likely have only reduced the magnitude of observed associations between profile membership and income or ESL status.

Finally, even with access to child health records from government MSP data, there were several variables unavailable to us that could be included in future research to further elucidate how social factors may be related to children's early social-emotional health. For example, parents' educational attainment, occupational status and mental health history would be relevant factors to include in future analyses, given their known association with child mental health outcomes. ${ }^{9} 2768$ Relatedly, an important question for future research to address is how regional context may influence the number and composition of child social-emotional profiles observed, as well as the strength of association with 
sociodemographic factors. For example, BC is a relatively high income province in Canada and is also the most culturally diverse, with almost $30 \%$ of residents identifying as a visible minority ${ }^{73}$ However, within parts of BC there is also significant child poverty and lack of cultural diversity that may be associated with distinct regional social-emotional outcomes for children. ${ }^{74} 75$ Similarly, the social-emotional health profiles identified in this study represent children's development at school entry and should not be used to extrapolate to children of different ages. Developmentally, one would expect relevant indicators of social-emotional health to change as children mature and face different stressors socially, psychologically and academically. ${ }^{76} 77$

\section{Conclusions}

Our results showed that commonly occurring patterns of early social-emotional problems can be distinguished in children as young as school entry, and that sociodemographic factors such as household income, child gender and ESL status are differentially associated with these patterns. Given the prevalence of social-emotional vulnerabilities within the entire population sample, and their ubiquity across sociodemographic factors, we suggest that interventions should include programming that addresses underlying issues that may be impairing children's social-emotional development at a population level in addition to universal, strengths-based programmes designed to promote young children's social-emotional health. ${ }^{2578}$

Acknowledgements We would like to acknowledge the children and teachers involved in this study, the implementation, knowledge translation, data management teams at the Human Early Learning Partnership and Population Data $\mathrm{BC}$, and the $\mathrm{BC}$ Ministries of Health and Education. We would also like to thank the Canadian Institutes of Health Research for funding this work.

Contributors KCT, MG, CGR and JS designed the study. TKA provided guidance on statistical analyses. KCT conducted the analyses and prepared the initial draft. All authors edited and approved the final manuscript.

Funding KCT was supported by a Canadian Institutes of Health Research (CIHR) Doctoral Research Award (GSD-134926). MG was supported by the Lawson Foundation, Canada.

Disclaimer Please note, all inferences, opinions, and conclusions drawn in this research article are those of the authors, and do not reflect the opinions or policies of the data stewards.

\section{Competing interests None declared.}

Patient consent Detail has been removed from this case description/these case descriptions to ensure anonymity. The editors and reviewers have seen the detailed information available and are satisfied that the information backs up the case the authors are making.

Ethics approval Ethics for this study was obtained from the University of British Columbia Research Ethics Board (H09-01962).

Provenance and peer review Not commissioned; externally peer reviewed.

Data sharing statement The data sets analysed in the current study are available in the Population Data BC repository (www.popdata.bc.ca/data).

Open Access This is an Open Access article distributed in accordance with the Creative Commons Attribution Non Commercial (CC BY-NC 4.0) license, which permits others to distribute, remix, adapt, build upon this work non-commercially, and license their derivative works on different terms, provided the original work is properly cited and the use is non-commercial. See: http://creativecommons.org/ licenses/by-nc/4.0/ (c) Article author(s) (or their employer(s) unless otherwise stated in the text of the article) 2017. All rights reserved. No commercial use is permitted unless otherwise expressly granted.

\section{REFERENCES}

1. Egger HL, Angold A. Common emotional and behavioral disorders in preschool children: presentation, nosology, and epidemiology. $J$ Child Psychol Psychiatry 2006;47(3-4):313-37.

2. Mathiesen KS, Sanson A, Stoolmiller M, et al. The nature and predictors of undercontrolled and internalizing problem trajectories across early childhood. J Abnorm Child Psychol 2009;37:209-22.

3. Bornstein MH, Hahn CS, Haynes OM. Social competence, externalizing, and internalizing behavioral adjustment from early childhood through early adolescence: developmental cascades. Dev Psychopathol 2010;22:717-35.

4. Fernandez Castelao C, Kröner-Herwig B. Different trajectories of depressive symptoms in children and adolescents: predictors and differences in girls and boys. J Youth Adolesc 2013;42:1169-82.

5. Dekker MC, Ferdinand RF, van Lang ND, et al. Developmental trajectories of depressive symptoms from early childhood to late adolescence: gender differences and adult outcome. J Child Psychol Psychiatry 2007;48:657-66.

6. Kuny AV, Althoff RR, Copeland W, et al. Separating the domains of oppositional behavior: comparing latent models of the Conners' Oppositional Subscale. J Am Acad Child Adolesc Psychiatry 2013;52:172-83.

7. Denham SA, Blair KA, DeMulder E, et al. Preschool emotional competence: pathway to social competence? Child Dev 2003;74:238-56.

8. Riggs NR, Jahromi LB, Razza RP, et al. Executive function and the promotion of social-emotional competence. J Appl Dev Psychol 2006;27:300-9.

9. Fanti KA, Henrich CC. Trajectories of pure and co-occurring internalizing and externalizing problems from age 2 to age 12: findings from the National Institute of Child Health and Human Development Study of Early Child Care. Dev Psychol 2010;46:1159-75.

10. Odgers CL, Moffitt TE, Broadbent JM, et al. Female and male antisocial trajectories: from childhood origins to adult outcomes. Dev Psychopathol 2008;20:673-716.

11. McGorry P, Keshavan M, Goldstone S, et al. Biomarkers and clinical staging in psychiatry. World Psychiatry 2014;13:211-23.

12. Blair $\mathrm{C}$. School readiness. Integrating cognition and emotion in a neurobiological conceptualization of children's functioning at school entry. Am Psychol 2002;57:111-27.

13. Alexander KL, Entwisle DR, Olson LS. Summer learning and its implications: insights from the Beginning School Study. New Dir Youth Dev 2007;114:11-32.

14. Hankin BL, Mermelstein R, Roesch L. Sex differences in adolescent depression: stress exposure and reactivity models. Child Dev 2007;78:279-95 http://www3.interscience.wiley.com/journal/ 117957201/abstract

15. Twenge JM, Nolen-Hoeksema S. Age, gender, race, socioeconomic status, and birth cohort differences on the children's depression inventory: a meta-analysis. J Abnorm Psychol 2002;111:578-88.

16. Duchesne S, Vitaro F, Larose S, et al. Trajectories of anxiety during elementary-school years and the prediction of high school noncompletion . J Youth Adolesc 2008;37:1134-46.

17. Nantel-Vivier A, Pihl RO, Côté S, et al. Developmental association of prosocial behaviour with aggression, anxiety and depression from infancy to preadolescence. J Child Psychol Psychiatry 2014;55:1135-44.

18. Wichstrøm L, Berg-Nielsen TS. Psychiatric disorders in preschoolers: the structure of DSM-IV symptoms and profiles of comorbidity. Eur Child Adolesc Psychiatry 2014;23:551-62.

19. Nandi A, Beard JR, Galea S. Epidemiologic heterogeneity of common mood and anxiety disorders over the lifecourse in the general population: a systematic review. BMC Psychiatry 2009;9:31.

20. Lanza ST, Rhoades BL. Latent class analysis: an alternative perspective on subgroup analysis in prevention and treatment. Prev Sci 2013;14:157-68.

21. Lubke GH, Muthén B. Investigating population heterogeneity with factor mixture models. Psychol Methods 2005;10:21-39.

22. Cuijpers P, Muñoz RF, Clarke GN, et al. Psychoeducational treatment and prevention of depression: the "Coping with Depression" course thirty years later. Clin Psychol Rev 2009;29:449-58.

23. Stice E, Shaw H, Bohon C, et al. A meta-analytic review of depression prevention programs for children and adolescents: 
factors that predict magnitude of intervention effects. $J$ Consult Clin Psychol 2009;77:486-503

24. Stice E, Rohde P, Seeley JR, et al. Brief cognitive-behavioral depression prevention program for high-risk adolescents outperforms two alternative interventions: a randomized efficacy trial. J Consult Clin Psychol 2008;76:595-606.

25. Durlak JA, Weissberg RP, Dymnicki AB, et al. The impact of enhancing students' social and emotional learning: a meta-analysis of school-based universal interventions. Child Dev 2011;82:405-32.

26. Collaboarative for Academic Social and Emotional Learning (CASEL) CASEL guide: effective social and emotional learning programs. Chicago, IL: Preschool and Elementary School Edition, 2013.

27. Basten MM, Althoff RR, Tiemeier $\mathrm{H}$, et al. The dysregulation profile in young children: empirically defined classes in the generation $\mathrm{R}$ study. J Am Acad Child Adolesc Psychiatry 2013;52:841-50.

28. Henninger WR, Luze G. Moderating effects of gender on the relationship between poverty and children's externalizing behaviors. J Child Health Care 2013;17:72-81.

29. Sterba SK, Prinstein MJ, Cox MJ. Trajectories of internalizing problems across childhood: heterogeneity, external validity, and gender differences. Dev Psychopathol 2007;19:345-66.

30. Denham SA, Bassett HH, Mincic M, et al. Social-emotional learning profiles of preschoolers' early school success: a person-centered approach. Learn Individ Differ 2012;22:178-89.

31. Cannon MF, Weems CF. Do anxiety and depression cluster into distinct groups?: a test of tripartite model predictions in a community sample of youth. Depress Anxiety 2006;23:453-60.

32. Wiggins $\mathrm{JL}$, Mitchell C, Hyde LW, et al. Identifying early pathways of risk and resilience: the codevelopment of internalizing and externalizing symptoms and the role of harsh parenting. Dev Psychopathol 2015;27:1295-312.

33. Kang HS, Haddad E, Chen C, et al. Limited english proficiency and socioemotional well-being among Asian and Hispanic children from immigrant families. Early Educ Dev 2014;25:915-31.

34. Huang KY, Cheng S, Calzada E, et al. Symptoms of anxiety and associated risk and protective factors in young Asian American children. Child Psychiatry Hum Dev 2012;43:761-74.

35. Costigan CL, Dokis DP. Relations between parent-child acculturation differences and adjustment within immigrant Chinese families. Child Dev 2006;77:1252-67.

36. Weeks M, Cairney J, Wild TC, et al. Early-life predictors of internalizing symptom trajectories in Canadian children. Depress Anxiety 2014;31:608-16.

37. Human Early Learning Partnership, BC Ministry of Health, BC Ministry of Education (2015): developmental trajectories linked data filePopulation Data BC. Vancouver, BC: University of British Columbia, School of Population and Public Health, 2015. http://www. popdata.bc.ca/data.

38. British Columbia School Act: chapter 412. Canada: Copyright the Queen's Printer, Victoria, British Columbia. http://www.bclaws.ca/ civix/document/id/complete/statreg/96412_00.

39. BC Schools. Student headcount by grade. https://catalogue.data. gov.bc.ca/dataset/bc-schools-student-headcount-by-grade/.

40. Frenette $M$, Chan $P$. Why are academic prospects brighter for private high school students? 2015. http://www.statcan.gc.ca/pub/11-626x/11-626-x2015044-eng.htm\#n8.

41. Janus M, Offord DR. Development and psychometric properties of the Early Development Instrument (EDI): a measure of children's school readiness. Can J Behav Sci 2007;39:1-22.

42. Guhn M, Gadermann A, Zumbo BD. Does the EDI measure school readiness in the same way across different groups of children? Early Educ Dev 2007:18:453-72.

43. Guhn M, Zumbo BD, Janus M, et al. Validation theory and research for a population-level measure of children's development, wellbeing, and school readiness. Soc Indic Res 2011;103:183-91.

44. Elder GH. The life course as developmental theory. Child Dev 1998;69:1-12.

45. Muthen LK, Muthen BO. Mplus user's guide. 7th edn. Los Angeles, CA: Muthen \& Muthen, 2015.

46. Muthen LK, Muthen BO. Chapter 7: examples: mixture modeling with cross-sectional data. Mplus User's Guide. 7th edn. Los Angeles, CA: Muthen \& Muthen, 2015:153-208

47. Berlin KS, Williams NA, Parra GR. An introduction to latent variable mixture modeling (part 1): overview and cross-sectional latent class and latent profile analyses. J Pediatr Psychol 2014;39:174-87.

48. Geiser C. Data analysis with MPlus. New York: Guildford Press, 2012:232-70.

49. Nylund KL, Asparouhov T, Muthén BO. Deciding on the number of classes in latent class analysis and growth mixture modeling: a Monte Carlo Simulation Study. Structural Equation Modeling: A Multidisciplinary Journal 2007;14:535-69.
50. Reef J, Diamantopoulou S, van Meurs I, et al. Developmental trajectories of child to adolescent externalizing behavior and adult DSM-IV disorder: results of a 24-year longitudinal study. Soc Psychiatry Psychiatr Epidemiol 2011;46:1233-41.

51. Janson H, Mathiesen KS. Temperament profiles from infancy to middle childhood: development and associations with behavior problems. Dev Psychol 2008;44:1314-28.

52. Van den Akker AL, Deković M, Asscher JJ, et al. Personality types in childhood: relations to latent trajectory classes of problem behavior and overreactive parenting across the transition into adolescence. $J$ Pers Soc Psychol 2013;104:750-64.

53. Bayer JK, Ukoumunne OC, Mathers M, et al. Development of children's internalising and externalising problems from infancy to five years of age. Aust N Z J Psychiatry 2012;46:659-68.

54. Bongers IL, Koot HM, van der Ende J, et al. Developmental trajectories of externalizing behaviors in childhood and adolescence. Child Dev 2004;75:1523-37.

55. Archambault I, Vandenbossche-Makombo J, Fraser SL. Students oppositional behaviors and engagement in school: the differential role of the student-teacher relationship. J Child Fam Stud 2017;11

56. Duckworth AL, Seligman MEP. Self-discipline gives girls the edge: gender in self-discipline, grades, and achievement test scores. $J$ Educ Psychol 2006;98:198-208.

57. Bruchmüller K, Margraf J, Schneider S. Is ADHD diagnosed in accord with diagnostic criteria? Overdiagnosis and influence of client gender on diagnosis. J Consult Clin Psychol 2012;80:128-38.

58. Sciutto MJ, Nolfi CJ, Bluhm C. Effects of child gender and symptom type on referrals for ADHD by elementary school teachers. $J$ Emot Behav Disord 2004;12:247-53.

59. Whalen DJ, Luby JL, Tilman R, et al. Latent class profiles of depressive symptoms from early to middle childhood: predictors, outcomes, and gender effects. J Child Psychol Psychiatry 2016;57:794-804.

60. Halle TG, Whittaker JV, Zepeda M, et al. The social-emotional development of dual language learners: looking back at existing research and moving forward with purpose. Early Child Res $Q$ 2014;29:734-49.

61. Phinney JS, Horenczyk G, Liebkind K, et al. Ethnic identity, immigration, and well-being: an interactional perspective. J Soc Issues 2001;57:493-510.

62. Huang KY, Cheng S, Theise R. School contexts as social determinants of child health: current practices and implications for future public health practice. Public Health Rep 2013;128:21-8.

63. McGuire S, Shanahan L. Sibling experiences in diverse family contexts. Child Dev Perspect 2010;4:72-9.

64. Pachter LM, Coll CG. Racism and child health: a review of the literature and future directions. J Dev Behav Pediatr 2009;30:255-63.

65. Nicholson JM, Lucas N, Berthelsen D, et al. Socioeconomic inequality profiles in physical and developmental health from 0-7 years: Australian National Study. J Epidemiol Community Health 2012;66:81-7.

66. Apouey B, Geoffard PY. Family income and child health in the UK. $J$ Health Econ 2013;32:715-27.

67. Elovainio $M$, Pulkki-Råback L, Jokela $M$, et al. Socioeconomic status and the development of depressive symptoms from childhood to adulthood: a longitudinal analysis across 27 years of follow-up in the Young Finns Study. Soc Sci Med 2012;74:923-9.

68. Najman JM, Aird R, Bor W, et al. The generational transmission of socioeconomic inequalities in child cognitive development and emotional health. Soc Sci Med 2004;58:1147-58.

69. Raat H, Wijtzes A, Jaddoe VW, et al. The health impact of social disadvantage in early childhood; the generation R study. Early Hum Dev 2011;87:729-33.

70. Reiss F. Socioeconomic inequalities and mental health problems in children and adolescents: a systematic review. Soc Sci Med 2013;90:24-31.

71. Guhn M, Gadermann AM, Almas A, et al. Associations of teacherrated social, emotional, and cognitive development in kindergarten to self-reported wellbeing, peer relations, and academic test scores in middle childhood. Early Child Res Q 2016;35:76-84.

72. Guhn M, Goelman H. Bioecological theory, early child development and the validation of the population-level early development instrument. Soc Indic Res 2011;103:193-217.

73. Statistics Canada. National Household Survey focus on geography series. http://www12.statcan.gc.ca/nhs-enm/2011/as-sa/fogs-spg/ Pages/FOG.cfm?lang=E\&level=2\&GeoCode=59.

74. First Call BC Child and Youth Advocacy Coalition. BC Child Poverty Report Card. 2016. http://still1in5.ca/report-card/.

75. Schwartz SJ, Unger JB, Zamboanga BL, et al. Rethinking the concept of acculturation: implications for theory and research. Am Psychol 2010;65:237-51. 
76. Eccles J. Schools, academic motivation and stage-environment fit. In: Lerner R, Steinberg L, eds. Handbook of adolescent development. Hoboken, NJ: Wiley, 2004:125-53.

77. Kessler RC, Berglund P, Demler O, et al. Lifetime prevalence and ageof-onset distributions of DSM-IV disorders in the National Comorbidity Survey replication. Arch Gen Psychiatry 2005;62:593-602.
78. Spoth R, Guyll M, Redmond C, et al. Six-year sustainability of evidence-based intervention implementation quality by communityuniversity partnerships: the PROSPER study. Am J Community Psychol 2011;48(3-4):412-25. 